\title{
What to do if a reader suspects undisclosed conflict of interest (Col) in a published article
}

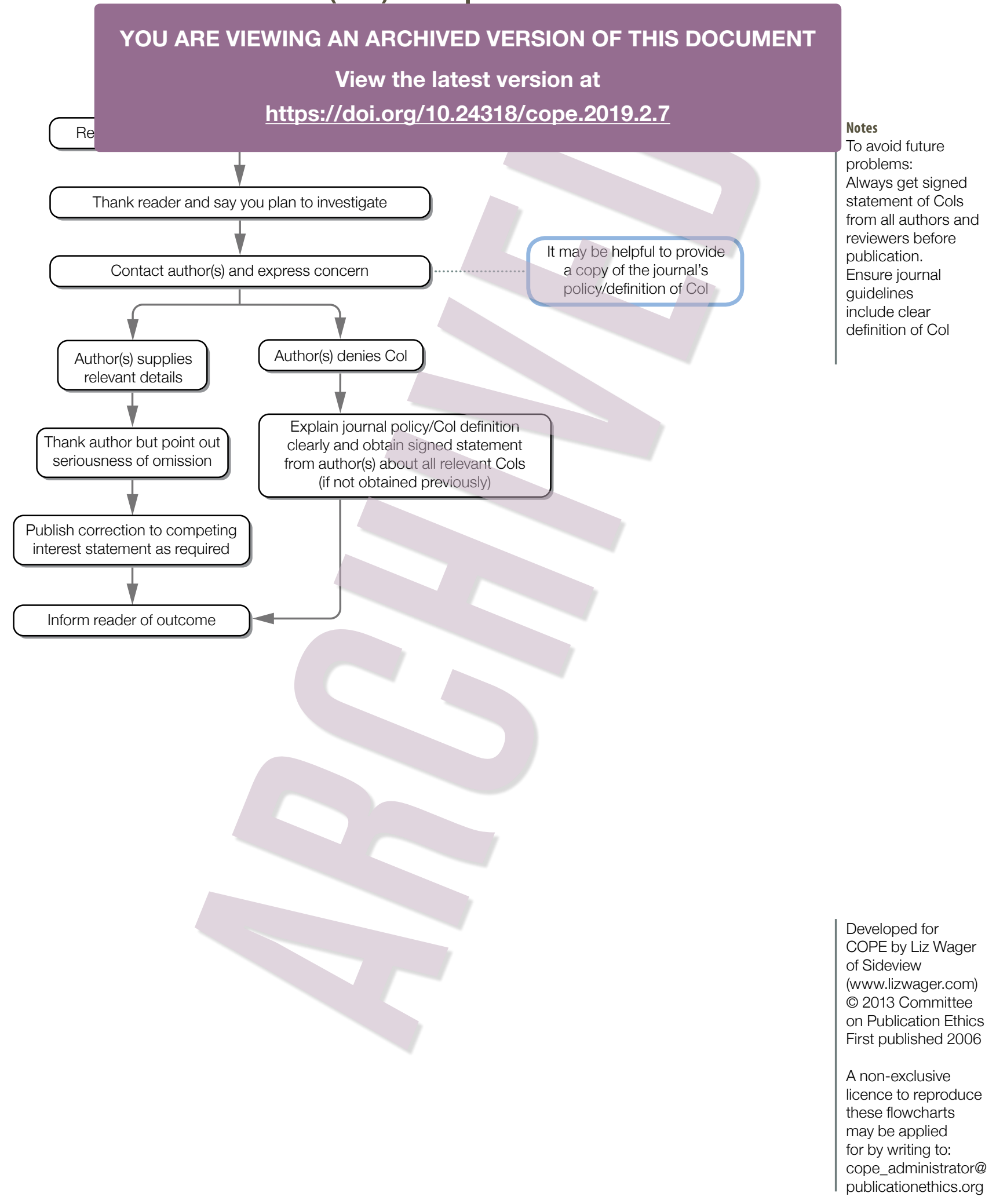

